\title{
Disruption of gul-1 decreased the culture viscosity and improved protein secretion in the filamentous fungus Neurospora crassa
} CrossMark

\author{
Liangcai Lin ${ }^{\dagger}$, Zhiyong Sun ${ }^{\dagger}$, Jingen Li, Yong Chen, Qian Liu, Wenliang Sun and Chaoguang Tian*
}

\begin{abstract}
Background: The cellulolytic fungus Neurospora crassa is considered a potential host for enzyme and bioethanol production. However, large scale applications are hindered by its filamentous growth. Although previous investigations have shown that mycelial morphology in submerged culture can be controlled by altering physical factors, there is little knowledge available about the potential for morphology control by genetic modification.
\end{abstract}

Results: In this study, we screened morphological mutants in the filamentous fungus N. crassa. Of the 90 morphological mutants screened, 14 mutants exhibited considerably higher viscosity compared with that of the wild type strain, and only two mutants showed low-viscosity morphologies in submerged culture. We observed that disruption of gul-1 (NCU01197), which encodes an mRNA binding protein involved in cell wall remodeling, caused pellet formation as the fermentation progressed, and resulted in the most significant decrease in viscosity of culture broth. Moreover, over-expression of gul-1 caused dramatically increased viscosity, suggesting that the gul- 1 had an important function in mycelial morphology during submerged cultivation. Transcriptional profiling showed that expression of genes encoding eight GPI-anchored cell wall proteins was lowered in $\triangle g u l-1$ while expression of genes associated with two non-anchored cell wall proteins was elevated. Meanwhile, the expression levels of two hydrophobin genes were also significantly altered. These results suggested that GUL-1 affected the transcription of cell wall-related genes, thereby influencing cell wall structure and mycelial morphology. Additionally, the deletion of gul-1 caused increased protein secretion, probably due to a defect in cell wall integrity, suggesting this as an alternative strategy of strain improvement for enzyme production. To confirm practical applications, deletion of gul-1 in the hyper-cellulase producing strain ( $\triangle n c w-1 \Delta N c a p 3 m)$ significantly reduced the viscosity of culture broth.

Conclusions: Using the model filamentous fungus N. crassa, genes that affect mycelial morphology in submerged culture were explored through systematic screening of morphological mutants. Disrupting several candidate genes altered viscosities in submerged culture. This work provides an example for controlling fungal morphology in submerged fermentation by genetic engineering, and will be beneficial for industrial fungal strain improvement.

Keywords: Neurospora crassa, Mycelial morphology, Pellet, Viscosity, Protein secretion

\section{Background}

Filamentous fungi are widely used for industrial scale production of antibiotics, proteins and many other useful chemicals [1-3]. Unlike bacteria and yeast, filamentous

\footnotetext{
*Correspondence: tian_cg@tib.cas.cn

${ }^{\dagger}$ Liangcai Lin and Zhiyong Sun contributed equally to this work Key Laboratory of Systems Microbial Biotechnology, Tianjin Institute of Industrial Biotechnology, Chinese Academy of Sciences, Tianjin 300308, China
}

fungi are morphologically complex microorganisms, which often leads to lots of process engineering problems during the fermentation process. When grown in submerged culture, fungi display different morphological forms, such as freely dispersed mycelia, clumps and pellets [4]. In general, the clump form predominates in fungal fermentations, resulting in high viscosity and a fermentation broth that shows several non-Newtonian characteristics. Although these disadvantages may not 
significant impact preliminary Erlenmeyer flask batch fermentations, when scaled up there are negative impacts on nutrient consumption and oxygen uptake, and a decrease in productivity. The simplest strategy to overcome this problem is to increase agitation speed. However, high impeller speed increases power consumption, and produces high shear stress that often damages fungal mycelia reducing product yield [5]. In contrast, the pellet growth form leads to Newtonian rheological behavior and low viscosities. As expected, lower power inputs are required for achieving sufficient agitation and mass transfer. Thus, the pellet morphology is preferred for many industrial processes, and it would greatly facilitate cost-effective production if one could design a way of controlling mycelial morphology during the fermentation process.

Many studies have reported on the effects of cultivation conditions and physical factors on fungal morphology, including media constituents, inoculum size, $\mathrm{pH}$, temperature, agitation systems and the type of fermenter [5-8]. Since the genetics of morphogenesis is very complicated in filamentous fungi, there is little knowledge available about morphology control through genetic modification. In recent years, chemical and UV mutagenesis strategies have been widely used to create mutants that show lowviscosity morphology in submerged culture [9]. However, random mutagenesis is quite time-consuming, and it is also difficult to determine which gene is responsible for a desired phenotype.

In the past century, the filamentous fungus Neurospora crassa has been used as a model organism for genetic and molecular studies [10], leading to a range of genetic techniques and tools [11]. Compared with other filamentous fungi, only $N$. crassa possesses a near full genome deletion strain collection. Recently, $N$. crassa was deployed as a model to unravel mechanisms of lignocellulase expression and regulation due to its capacity to secrete lots of enzymes involved in lignocellulose utilization [12]. In addition, $N$. crassa has been reported to be a potential alternative candidate for heterologous protein expression and bioethanol production [13]. Several approaches have been employed to improve cellulase production, including regulation of the cellulase induction pathway, regulation of the unfolded protein response pathway, and by enhancing protein secretion [14-16]. Furthermore, $N$. crassa can be easily sexually crossed to generate multiple-gene mutants, which facilitates construction of hyper-cellulase producers. However, to our knowledge, $N$. crassa has not been used in industrial scale processes. One of the most limiting factors is its mycelial morphology in submerged culture. The $N$. crassa wild type strain exhibits a clump type of morphology, which results in high viscosity and mass transfer limitations. Although it is reported that $N$. crassa can grow as dispersed pellets following the addition of Triton $\mathrm{N}-101$ or anionic polymer carboxypolymethylene [17, 18], investigations into the molecular controls of morphology could have great significance in industrial application.

Therefore, we screened $90 \mathrm{~N}$. crassa morphological mutants to identify putative genes affecting mycelial morphology during submerged cultivation. Several candidate genes affected the viscosity of media when disrupted in N. crassa. Intriguingly, we found that disruption of gul-1 (NCU01197), the homolog of Saccharomyces cerevisiae ssd1, led to a significant change in viscosity. In S. cerevisiae, SSD1 plays critical roles in maintaining cell wall integrity [19], and has been found to specifically associate with the mRNAs of proteins that are involved in cell wall remodeling [20]. SSD1 is also negatively regulated by the NDR family kinase Cbk1 through phosphorylation [21]. Deletion of $s s d 1$ alters the composition and cell wall architecture of the yeast cell surface [22]. Similar to the functions described for SSD1, GUL-1 is an important component of the NDR kinase COT-1 pathway, which is involved in the regulation of polarized growth in $N$. crassa $[23,24]$. The NDR family kinase COT-1, which is a homolog of the $S$. cerevisiae Cbk 1 , is required for normal hyphal elongation [25]. The temperaturesensitive cot-1 mutant exhibits cessation of tip extension and hyperbranching after being shifted to restrictive temperature. Disruption of gul-1 can partially suppress the growth defects of $\cot -1$. Thus, $g u l-1$ has been initially identified as a dominant modifier of cot-1 [26]. Further investigation demonstrated that the Ste20 kinase POD-6 is involve in polar tip extension and also acts in the NDR kinase COT-1 pathway. The growth defects in pod-6 and cot-1 can be suppressed by the common extragenic suppressor, gul-1, suggesting that gul-1 may function as a downstream mediator in this pathway [23]. Recently, Herold and Yarden provided strong evidence to support this hypothesis. Their results illuminated that the NDR family kinase COT-1 affects hyphal growth by influencing the transcript levels of cell wall remodeling genes, which is mediated by gul-1 [24]. Despite the previous studies described above, the mechanism of how gul-1 affects mycelial morphology in submerged culture remains unclear. In this study, we demonstrated that gul-1 alters cell wall structure by influencing the expression of cell wall protein genes, which leading to changes in mycelial morphology. In addition, we also illustrated that morphology engineering enables enhanced protein secretion. Our findings enhance our understanding of the genetics of morphogenesis in filamentous fungi and provided a novel strategy for morphological engineering of filamentous fungi by genetic modification. 


\section{Results}

\section{A low-viscosity mutant from a morphological mutant library}

Colot et al. [27] constructed a nearly complete genome disruption mutant collection. There were two 96-well plates in this collection relevant to our study. One plate was annotated as "Morphologicals", the other was identified as "Hyphal Growth Set" [28]. To identify the key genes that play important roles in mycelial morphology during submerged cultivation, we screened these $90 N$. crassa morphological mutants. The viscosities of the fermentation broths are shown in Fig. 1 and Table 1. According to microscope observations, the majority of mutants resembled the wild type (WT) in growth characteristics. Compared to WT, 14 mutants showed dramatically increased viscosity (>50\%) and two mutants showed decreased viscosity (>50\%). Deletion of NCU03938 (encoding an alternative oxidase-5) reduced viscosity by approximately $55 \%$, but this mutant still grew as clumps. Conversely, loss of NCU01197, which was annotated as gul-1 previously [23], resulted in the pellet growth form and reduced viscosity by more than $80 \%$ compared with WT. Thus, gul-1 was selected for further investigation.

\section{GUL-1 is involved in mycelial morphology in N. crassa}

In order to determine the extent of the morphological changes conferred by gul-1 disruption, we conducted a microscopic analysis of $\Delta g u l-1$ grown under permissive temperature. When grown on agar plates at $25^{\circ} \mathrm{C}$, there were significant differences in hyphal elongation and branching frequency between $\Delta g u l-1$ and WT. The $\Delta g u l$ 1 exhibited slow growth rate and hyperbranching (Additional file 1: Figure S1), which is consistent with previous

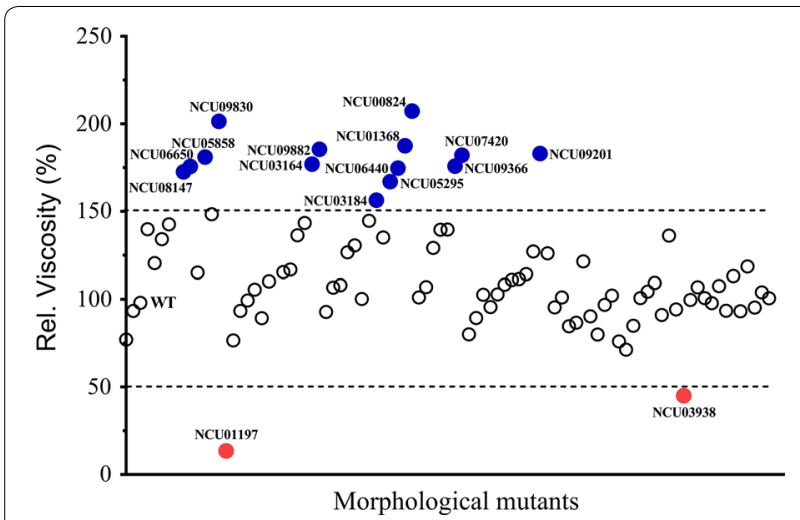

Fig. 1 Screening of 90 morphological mutants in Neurospora crassa. Conidia from the wild type (WT) and morphological mutants were separately inoculated into Avicel medium and batch cultured for 7 days. The viscosities of culture broths altered by more than $50 \%$ compared with the WT are indicated as follows: blue dots, high-viscosity mutants; red dots, low-viscosity mutants observations [23]. These results indicated that disruption of gul-1 substantially impact hyphal development in $N$. crassa.

A detailed analysis of the effects of disrupting gul-1 on the rheological properties of mycelial broth was also performed. Conidia of WT and $\Delta g u l-1$ were inoculated into Avicel medium and batch cultured for 7 days. The viscosity of WT increased to $557 \pm 44 \mathrm{cp}$ in the first $72 \mathrm{~h}$ before stabilizing until $120 \mathrm{~h}$ when the viscosity decreased significantly (Fig. 2). However, the rheological properties of $\Delta g u l-1$ cultures were quite different from that of the WT. Firstly, the viscosity of $\Delta g u l-1$ was much higher than that of WT $48 \mathrm{~h}$ post-inoculation, with its viscosity then decreasing dramatically during the time course of batch fermentation. After 7 days fermentation, the viscosity of $\Delta g u l-1$ was only one-fifth that of WT (Fig. 2). According to microscopic observations, the WT showed a clump type of morphology. However, $\Delta g u l-1$ grew as pellets that became more compact as fermentation progressed (Fig. 2). The diameter of pellets was about $350 \pm 62 \mu \mathrm{m}$. Furthermore, scanning electron microscopy demonstrated that $\Delta g u l-1$ exhibited much smoother surface than the WT (Additional file 2: Figure S2).

It is well established that mycelial biomass significantly affects the apparent viscosity of fermentation broth. Thus, the biomass of $\Delta g u l-1$ and WT were determined as described [14]. The results revealed that the dry weight of $\Delta g u l-1$ was similar to that of the WT (Additional file 3: Figure S3). Thus, the change in rheological properties was due to the morphological change in mycelia, and not to a reduction in biomass.

In addition, fungal morphology in submerged cultures is affected by the type of carbon source [29]. The $\Delta g u l-1$ grew as pellets, and exhibited dramatically reduced viscosity (>50\%) compared with that of WT when grown on glucose, xylose and fructose (Additional file 4: Figure S4) indicated that growth form is independent of the type of carbon source. This suggests that gul-1 might be considered as a universal target for morphology control under different cultivation conditions.

To the best of our knowledge, this is the first report indicating that $N$. crassa can change morphological forms in submerged culture (from clump type to pellet type) through genetic modification.

\section{Expression level of $g$ ul- 1 affected culture viscosity}

To determine whether $g u l-1$ expression levels affect the rheological properties of $N$. crassa fermentation, we engineered the $\Delta g u l-1$ strain to express a C-terminal GFPtagged GUL-1 under the regulation of either the native gul-1 promoter (strain Pn-gul-1, complemented strain) or the constitutive $c c g-1$ promoter (strain Pc-gul-1, gul1 over-expression strain). Complemented Pn-gul-1 was 
Table 1 List of morphological mutants in Neurospora crassa

\begin{tabular}{|c|c|c|c|c|}
\hline No. & NCU no. & Annotation & Viscosity (cP) & $\begin{array}{l}\text { Increased } \\
\text { vs WT (\%) }\end{array}$ \\
\hline 1 & NCU07075 & Calcium exchanger & $267.5 \pm 3.5$ & -22.9 \\
\hline 2 & NCU09866 & Thyroid hormone receptor interactor 12 & $324.5 \pm 34.6$ & -6.5 \\
\hline 3 & NCU09423 & Secreted protein & $340.5 \pm 12.0$ & -1.9 \\
\hline 4 & NCU05854 & Hypothetical protein & $430.0 \pm 127.3$ & 23.9 \\
\hline 5 & NCU05790 & Phytochrome-2 & $418.5 \pm 9.2$ & 20.6 \\
\hline 6 & NCU05956 & Glycosylhydrolase family $2-2$ & $466.0 \pm 36.8$ & 34.3 \\
\hline 7 & NCU07617 & Aconidiate-3 & $407.5 \pm 88.5$ & 17.4 \\
\hline 8 & NCU08147 & P-type ATPase & $599.0 \pm 58.0$ & 72.6 \\
\hline 9 & NCU06650 & Secretory phospholipase A2 & $610.0 \pm 56.6$ & 75.8 \\
\hline 10 & NCU06531 & Hypothetical protein & $458.0 \pm 116.0$ & 32.0 \\
\hline 11 & NCU05858 & Fatty acid oxygenase & $630.0 \pm 42.4$ & 81.6 \\
\hline 12 & NCU06419 & MAPKJERK kinase & $495.0 \pm 41.4$ & 42.6 \\
\hline 13 & NCU09830 & Menadione-induced gene-12 & $700.0 \pm 28.3$ & 101.7 \\
\hline 14 & NCU01197 & Gulliver-1 & $42.0 \pm 2.8$ & -87.9 \\
\hline 15 & NCU09364 & Heat shock protein 30 & $261.0 \pm 26.9$ & -24.8 \\
\hline 16 & NCU06265 & Hypothetical protein & $324.5 \pm 54.4$ & -6.5 \\
\hline 17 & NCU01213 & Superoxide dismutase-2 & $345.0 \pm 83.4$ & -0.6 \\
\hline 18 & NCU09494 & Hypothetical protein & $366.5 \pm 75.7$ & 5.6 \\
\hline 19 & NCU08741 & Hyphal anastomosis-3 & $380.0 \pm 127.3$ & 9.5 \\
\hline 20 & NCU03894 & Serine/threonine protein kinase- 4 & $382.5 \pm 95.5$ & 10.2 \\
\hline 21 & NCU01833 & Nonidentical kinase-2 & $401.0 \pm 79.2$ & 15.6 \\
\hline 22 & NCU02542 & Embden-meyerhof pathway-1 & $406.0 \pm 19.8$ & 17.0 \\
\hline 23 & NCU01181 & Acyl-CoA dehydrogenase-3 & $473.5 \pm 79.9$ & 36.5 \\
\hline 24 & NCU08225 & High affinity nickel transporter nic1 & $498.0 \pm 46.7$ & 43.5 \\
\hline 25 & NCU03164 & Two-component system response regulator & $615.0 \pm 62.2$ & 77.2 \\
\hline 26 & NCU09882 & Metacaspase-1A & $644.5 \pm 21.9$ & 85.7 \\
\hline 27 & NCU09450 & Regulatory particle, non-ATPase-like-2 & $322.5 \pm 64.3$ & -7.1 \\
\hline 28 & NCU02260 & Regulatory particle, ATPase-like-3 & $370.5 \pm 43.1$ & 6.8 \\
\hline 29 & NCU00634 & Ribosomal protein L14 & $375.0 \pm 77.8$ & 8.1 \\
\hline 30 & NCU03702 & rRNA 2'-O-methyltransferase fibrillarin & $440.0 \pm 67.9$ & 26.8 \\
\hline 31 & NCU08050 & Hypothetical protein & $453.5 \pm 50.2$ & 30.7 \\
\hline 32 & NCU06764 & Proteasome catalytic alpha-2 & $490.0 \pm 155.6$ & 41.2 \\
\hline 33 & NCU00396 & Pre-mRNA-splicing factor rse-1 & $502.5 \pm 51.6$ & 44.8 \\
\hline 34 & NCU03184 & $\mathrm{C} 2 \mathrm{H} 2$ conidiation transcription factor FlbC & $543.0 \pm 28.3$ & 56.5 \\
\hline 35 & NCU02604 & Hypothetical protein & $456.0 \pm 33.9$ & 31.4 \\
\hline 36 & NCU05295 & Proteasome catalytic alpha-5 & $580.5 \pm 26.2$ & 67.3 \\
\hline 37 & NCU06440 & Proteasome catalytic alpha-4 & $607.5 \pm 41.7$ & 75.1 \\
\hline 38 & NCU01368 & Proteasome catalytic beta- 4 & $651.5 \pm 68.6$ & 87.8 \\
\hline 39 & NCU00824 & Histone deacetylase-3 & $720.0 \pm 14.1$ & 107.5 \\
\hline 40 & NCU06429 & Alpha-actinin & $351.0 \pm 38.2$ & 1.2 \\
\hline 41 & NCU00554 & Homoserine-1 & $371.5 \pm 64.3$ & 7.1 \\
\hline 42 & NCU08093 & Hypothetical protein & $448.5 \pm 78.5$ & 29.3 \\
\hline 43 & NCU00105 & 605 ribosome subunit biogenesis protein NIP7 & $484.5 \pm 17.7$ & 39.6 \\
\hline 44 & NCU03479 & Endoribonuclease ysh-1 & $485.0 \pm 77.8$ & 39.8 \\
\hline 45 & NCU09366 & Proteasome catalytic beta- 6 & $611.0 \pm 55.2$ & 76.1 \\
\hline 46 & NCU07420 & elF4A & $633.0 \pm 53.7$ & 82.4 \\
\hline 47 & NCU00467 & COP9 signalosome-5 & $267.5 \pm 17.7$ & -22.9 \\
\hline 48 & NCU01408 & COP9 signalosome-3 & $310.5 \pm 0.7$ & -10.5 \\
\hline 49 & NCU00923 & Topogenesis of outer membrane beta barrel protein 37 & $336.5 \pm 19.1$ & -3.0 \\
\hline
\end{tabular}


Table 1 (continued)

\begin{tabular}{|c|c|c|c|c|}
\hline No. & NCU no. & Annotation & Viscosity (cP) & $\begin{array}{l}\text { Increased } \\
\text { vs WT (\%) }\end{array}$ \\
\hline 50 & NCU04669 & Hypothetical protein & $332.0 \pm 72.1$ & -4.3 \\
\hline 51 & NCU04242 & Period-6 & $357.0 \pm 42.4$ & 2.9 \\
\hline 52 & NCU02057 & Autoinducer 2 sensor kinase/phosphatase luxQ & $376.0 \pm 1.4$ & 8.4 \\
\hline 53 & NCU09842 & Mitogen activated protein kinase-1 & $385.5 \pm 33.2$ & 11.1 \\
\hline 54 & NCU01033 & Hypothetical protein & $387.0 \pm 83.4$ & 11.5 \\
\hline 55 & NCU08875 & Cullin binding protein CanA & $397.0 \pm 49.5$ & 14.4 \\
\hline 56 & NCU00810 & Glycosylhydrolase family 2-3 & $436.5 \pm 19.1$ & 25.8 \\
\hline 57 & NCU09201 & Hypothetical protein & $636.0 \pm 58.0$ & 83.3 \\
\hline 58 & NCU04096 & Protein kinase-9 & $462.9 \pm 18.3$ & 33.4 \\
\hline 59 & NCU00204 & Hypothetical protein & $306.3 \pm 33.6$ & -11.7 \\
\hline 60 & NCU00355 & Catalase-3 & $331.1 \pm 26.7$ & -4.6 \\
\hline 61 & NCU01225 & Ubiquitin conjugating enzyme & $259.0 \pm 29.8$ & -25.4 \\
\hline 62 & NCU01312 & Regulator of conidiation in Aspergillus-1 & $336.1 \pm 33.8$ & -3.1 \\
\hline 63 & NCU01613 & Protoperithecia-2 & $372.0 \pm 31.1$ & 7.2 \\
\hline 64 & NCU01642 & Hypothetical protein & $283.8 \pm 22.9$ & -18.2 \\
\hline 65 & NCU02133 & Superoxide dismutase-1 & $262.7 \pm 24.5$ & -24.3 \\
\hline 66 & NCU02387 & Nuclear import and export protein Msn5 & $306.3 \pm 33.6$ & -11.7 \\
\hline 67 & NCU02498 & Cullin-3 & $334.9 \pm 21.4$ & -3.5 \\
\hline 68 & NCU02794 & Soft & $269.0 \pm 43.9$ & -22.5 \\
\hline 69 & NCU03013 & Anchored cell wall protein-10 & $277.7 \pm 45.7$ & -20.0 \\
\hline 70 & NCU03076 & Delta-1-pyrroline-5-carboxylate dehydrogenase & $305.0 \pm 21.2$ & -12.1 \\
\hline 71 & NCU03125 & NIMA-interacting protein TinC & $304.9 \pm 21.0$ & -12.1 \\
\hline 72 & NCU03281 & Transport of copper-2 & $347.3 \pm 18.0$ & 0.1 \\
\hline 73 & NCU03314 & mob2-like-a & $364.6 \pm 20.6$ & 5.1 \\
\hline 74 & NCU03623 & Ubiquitin-conjugating enzyme $\mathrm{E}$ & $291.3 \pm 12.4$ & -16.1 \\
\hline 75 & NCU06175 & Peroxin 3 & $473.0 \pm 38.1$ & 36.3 \\
\hline 76 & NCU06255 & Hypothetical protein & $317.4 \pm 17.8$ & -8.5 \\
\hline 77 & NCU03938 & Alternative oxidase- 5 & $156.9 \pm 32.6$ & -54.8 \\
\hline 78 & NCU04264 & Extracellular developmental signal biosynthesis protein FluG & $331.1 \pm 26.7$ & -4.6 \\
\hline 79 & NCU04302 & Ubiquitin-conjugating enzyme E & $331.0 \pm 15.6$ & -4.6 \\
\hline 80 & NCU04513 & Ubiquitin conjugating enzyme Ubc14 & $364.6 \pm 20.6$ & 5.1 \\
\hline 81 & NCU04533 & Abundant perithecial protein & $339.9 \pm 28.5$ & -2.1 \\
\hline 82 & NCU04834 & Phytochrome-1 & $373.4 \pm 23.4$ & 7.6 \\
\hline 83 & NCU05046 & E1-E2 ATPase-1 & $329.7 \pm 27.9$ & -5.0 \\
\hline 84 & NCU05591 & ABC transporter CDR4 & $353.3 \pm 47.1$ & 1.8 \\
\hline 85 & NCU07378 & Serine/threonine protein kinase-12 & $323.7 \pm 37.2$ & -6.7 \\
\hline 86 & NCU07728 & Siderophore regulation & $416.9 \pm 9.8$ & 20.1 \\
\hline 87 & NCU08055 & b-ZIP transcription factor IDI4 & $331.1 \pm 26.7$ & -4.6 \\
\hline 88 & NCU08791 & Catalase-1 & $361.0 \pm 26.9$ & 4.0 \\
\hline 89 & NCU03725 & Vegetative incompatibility blocked-1 & $415.7 \pm 20.2$ & 19.8 \\
\hline 90 & NCU03043 & $\mathrm{C} 2 \mathrm{H} 2$ finger domain-containing protein $\mathrm{FlbC}$ & $356.0 \pm 19.8$ & 2.6 \\
\hline
\end{tabular}

indistinguishable from WT in any of the phenotypic assays performed in this study (data not shown). The Pcgul-1 strain showed WT growth rates on MM agar (Additional file 5: Table S1) and WT clump type morphology in submerged culture, but the viscosity was approximately $50 \%$ greater than that of WT (Fig. 3). These results indicate that gul-1 plays important roles in controlling mycelial morphology during submerged cultivation. 


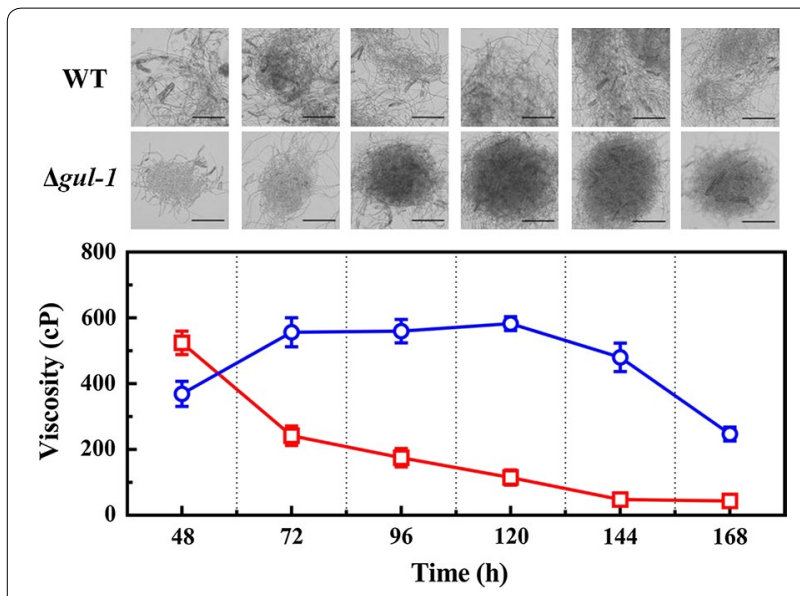

Fig. 2 Mycelial morphologies of wild type and $\Delta g u l-1$ mutant during submerged cultivation. Conidia from the wild type (WT) and gul-1 mutant ( $\triangle$ gul-1) were separately inoculated into Avicel medium and batch cultured for 7 days, and the viscosities of the broths were measured at $24 \mathrm{~h}$ intervals. The $\Delta$ gul-1 mutant grew in pellet form, whereas the wild type exhibited a clump type morphology. Blue line indicates WT; Red line indicates the $\Delta g u l-1$ mutant. Scale bar is $200 \mu \mathrm{m}$. Values represent the means of at least three replicates, error bars show standard deviation

\section{Subcellular localization of the GUL-1 protein in N. crassa}

To assess the subcellular localization of GUL-1 protein, we tracked the C-terminal GFP-tagged GUL-1 in the $\Delta g u l-1$ strain. Under its native promoter, GFP-tagged GUL-1 fluorescence was hard to observe in mycelia, but detectable in conidia (data not shown), indicating that gul-1 had a lower expression level in mycelium than conidia. When the GUL-1-GFP fusion encoding gene was under the control of the $c c g$ - 1 constitutive promoter, GFP fluorescence was uniformly distributed in the cytoplasm of both hyphae and conidia (Fig. 4), similar to that reported for the Colletotrichum lagenarium Classd1p [30]. However, recent studies have shown that S. cerevisiae Ssd1, the homolog of N. crassa GUL-1, transiently localizes to the nucleus [31]. To address whether GUL-1 also enters the nucleus, we surveyed GUL-1 for a signal sequence using NLStradamus which predicted a putative lysine-rich nuclear localization signal (amino acids 497507: KREKEEKKKRK) [32]. Thus, GUL-1 is probable a nucleocytoplasmic protein, which usually localizes to the cytoplasm. The detailed mechanism of nucleocytoplasmic shuttling of GUL-1 remains to be elucidated.

\section{Sensitivity to cell wall inhibitors and oxidative agents}

Our results indicate that gul-1 influences the mycelial morphology of $N$. crassa, so we determined whether $\Delta$ gul-1 suffers defects in cell wall integrity. We therefore examined its sensitivity to cell wall perturbation,

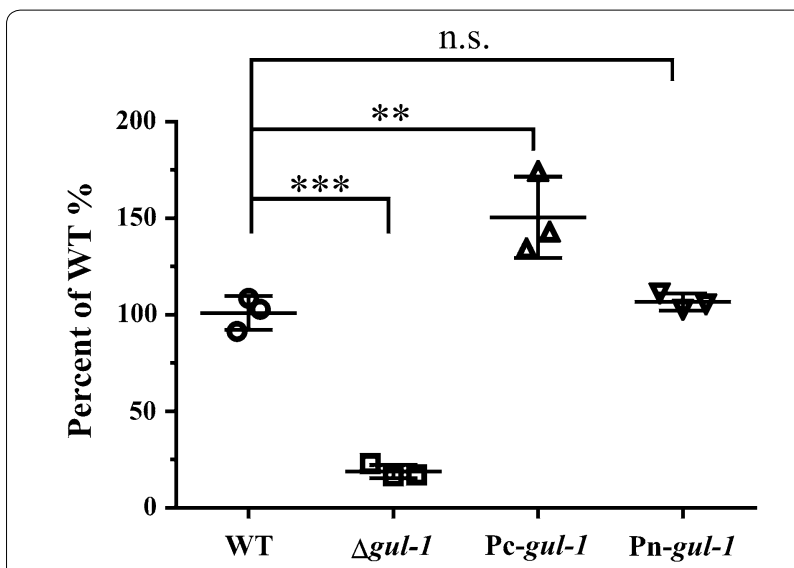

Fig. 3 Comparison of the viscosity of culture broths from WT, $\Delta$ gul-1, Pc-gul-1 and Pn-gul-1 strains grown on Avicel medium for 7 days. The following strains were grown in $2 \%(\mathrm{~W} / \mathrm{v})$ Avicel media: the WT, the gul-1 gene knockout mutant ( $\triangle$ gul- 1 ) and the complemented strain under either the control of the $c c_{-1}-1$ promoter ( $\left.\mathrm{Pc}-g u l-1\right)$ or the native promoter (Pn-gul-1). The viscosity was measured and displayed after normalization to the WT control according to percentage. Values represent the means of at least three biological replicates, error bars show standard deviation. Statistical significance was performed using a two-tailed Student's $t$ test ${ }^{* *} P<0.01$; ${ }^{* *} P<0.001$; n.s., not significant)

oxidative stress and high osmolarity. The results showed that $\Delta g u l-1$ had increased sensitivity to Congo Red, which binds to $\beta$-1,3-glucans and interferes with cell wall construction [33]. Growth of $\Delta g u l-1$ on MM containing $1 \mathrm{mg} / \mathrm{mL}$ Congo Red was reduced by $29.7 \pm 0.3 \%$, whereas growth of WT was only reduced by $17.7 \pm 0.5 \%$. Likewise, $\Delta g u l-1$ showed increased sensitivity to Calcofluor White, which disrupts cell wall synthesis by binding to chitin [34]. Growth of $\Delta g u l-1$ on MM supplemented with $200 \mu \mathrm{g} / \mathrm{mL}$ Calcofluor White was reduced by over $29.3 \pm 1.3 \%$, whereas growth of WT was only reduced by $19.1 \pm 2.1 \%$ (Fig. 5), suggesting that the mutant had altered cell wall integrity. These data are consistent with other studies, where deletion of the gul-1 homolog in the plant pathogen Magnaporthe grisea also resulted in hypersensitivity to Calcofluor White [30].

Oxidative stress was provided by hydrogen peroxide $\left(\mathrm{H}_{2} \mathrm{O}_{2}\right)$, diamide or methyl-viologen. These oxidants elicit oxidative damage to fungal cells in different ways. $\mathrm{H}_{2} \mathrm{O}_{2}$ is a common oxidative agent able to react with many biological molecules including proteins and DNA [35]. Diamide triggers oxidative stress by oxidizing intracellular glutathione [36]. Methyl-viologen is a redox cycling reagent that produces superoxide anions under aerobic condition [37]. All three oxidative agents partially inhibited the elongation of hyphae in both $\Delta g u l-1$ and WT strains; only diamide was more effective on $\Delta g u l-1$ than the WT (Fig. 5). The growth of $\Delta g u l-1$ on MM agar 


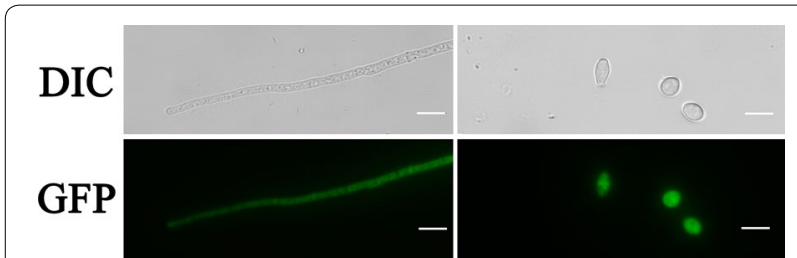

Fig. 4 The subcellular localization of GUL-1 in Neurospora crassa. Locations of GUL-1 proteins were monitored by recording enhanced green fluorescent protein signal. Microscopic observation was performed with an OLYMPUS BX51 microscope. Scale bar is $10 \mu \mathrm{m}$

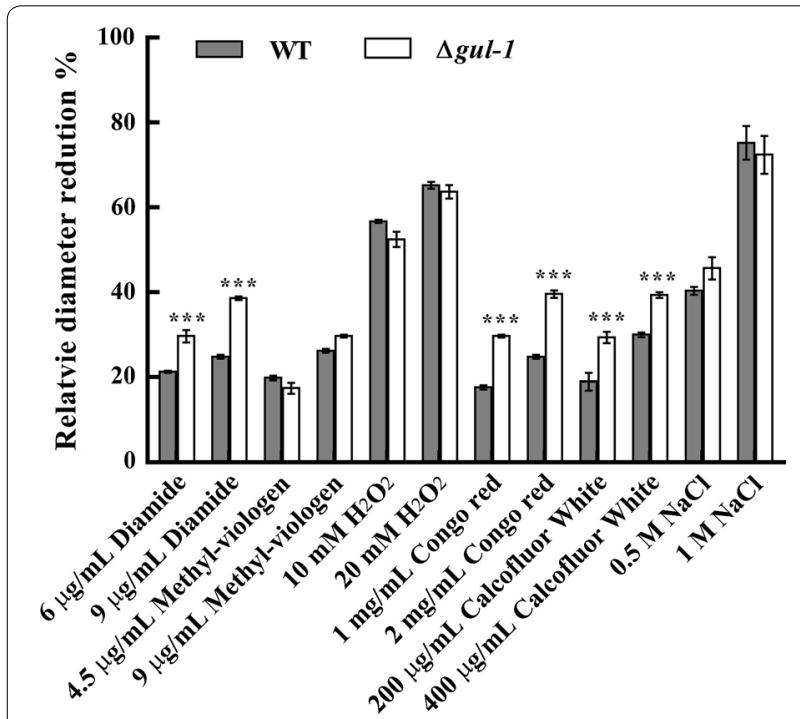

Fig. 5 Effect of different concentrations of chemicals on hyphal growth in WT and $\Delta$ gul-1. Aliquots of $5 \mu \mathrm{L} 1 \times 10^{7} \mathrm{~mL}^{-1}$ spore suspensions of WT and $\triangle$ gul- 1 were incubated at $28^{\circ} \mathrm{C}$ for $18 \mathrm{~h}$ on MM plates incorporating $\mathrm{H}_{2} \mathrm{O}_{2}(10,20 \mathrm{mM})$, diamide $(6,9 \mu \mathrm{g} / \mathrm{mL})$, methyl-viologen (4.5, $9 \mu \mathrm{g} / \mathrm{mL}), \mathrm{NaCl}(0.5,1.0 \mathrm{M})$, Congo Red (1, $2 \mathrm{mg} /$ $\mathrm{mL}$ ) or Calcofluor White $(200,400 \mathrm{\mu g} / \mathrm{mL})$, and then the diameter of each colony was measured. Relative diameter reduction means the reduction of growth rate on MM containing chemicals compared with the growth on MM only. Values represent the means of at least three biological replicates, error bars show standard deviation. Statistical significance was performed using a two-tailed Student's $t$ test $\left({ }^{* * *} P<0.001\right)$

containing $9 \mu \mathrm{g} / \mathrm{mL}$ diamide was reduced by $38.6 \pm 0.4 \%$ as compared to $24.8 \pm 0.5 \%$ for the WT. These results indicate that gul-1 has a role in glutathione-mediated antioxidant processes, but not in general oxidative stress protection of $N$. crassa.

$\Delta$ gul-1 grown on MM medium supplemented with $\mathrm{NaCl}$ exhibited no greater sensitivity to osmotic stress than the wild type strain (Fig. 5), indicating that gul-1 is not required for osmotic stress tolerance.

\section{Deletion of gul-1 improved protein secretion}

As a cellulolytic filamentous fungus, $N$. crassa possesses an extraordinary capacity to secret a wide variety of lignocellulolytic enzymes, making it a potential workhorse for production of industrial enzymes and high-value vaccines [38]. Based on our findings, we interrogated whether the defect in cell wall integrity would enhance protein secretion in $N$. crassa. The ability of WT and $\Delta g u l-1$ to secrete cellulases was compared in Avicel medium. The $\Delta g u l-1$ mutant secreted $25 \%$ more extracellular proteins 7 days post-inoculation. Although endoglucanase activity was unaffected, $\beta$-glucosidase activity in $\Delta g u l-1$ was $56 \%$ higher than that of WT (Fig. 6). We also assessed whether disrupting gul-1 would enhance protein secretion on other carbon sources. Compared with WT, the secreted protein titers in the $\Delta g u l-1$ strain were 181 , 57 and 43\% higher than those of WT strain on sucrose, fructose or xylose, respectively (Additional file 4: Figure S4), suggesting that the enhancement of protein secretion in the $\Delta g u l-1$ strain is independent of the carbon source. These results also indicate that cell wall integrity could play a critical role in protein secretion with implications for other filamentous fungi.

\section{Comparative analysis of transcriptomes of WT and the $\Delta$ gul- 1 strain}

Disruption of gul-1 in N. crassa caused pellet growth in submerged cultivation (Fig. 2). It is well established that fungal pellet formation is due to the combination of electrostatic interactions, hydrophobicity and specific interactions from cell wall components [39]. Based on the analysis above, we therefore hypothesized that the mechanism of pellet formation in $\Delta g u l-1$ might feasibly be explained by changes in cell wall organization. To test this hypothesis, we evaluated transcriptional changes in the $\Delta$ gul-1 mutant when grown on Avicel medium for 3 days using the WT as a control. RNA-seq data showed that the expression level of 101 genes was significantly lower in the $\Delta g u l-1$ mutant, while the expression level of 145 genes increased (Additional file 6: Table S2). It is worth noting that the expression levels of several cell wallrelated genes were significantly altered in $\Delta g u l-1$. These cell wall proteins are critical components of the fungal cell wall. Based on the manner in which they are attached to the cell wall polysaccharides, the cell wall proteins have been classified into two classes in $N$. crassa: GPIanchored cell wall protein (ACW) and non-anchored cell wall protein $(\mathrm{NCW})$ [40]. As previously reported, 22 cell wall proteins have been identified in $N$. crassa vegetative hyphae cell wall proteomic analysis [40]. Of the 22 identified genes, we detected 10 (45\%) genes with altered expression (Fig. 7a and Additional file 7: Table S3). Eight GPI-anchored cell wall protein genes showed a decrease 


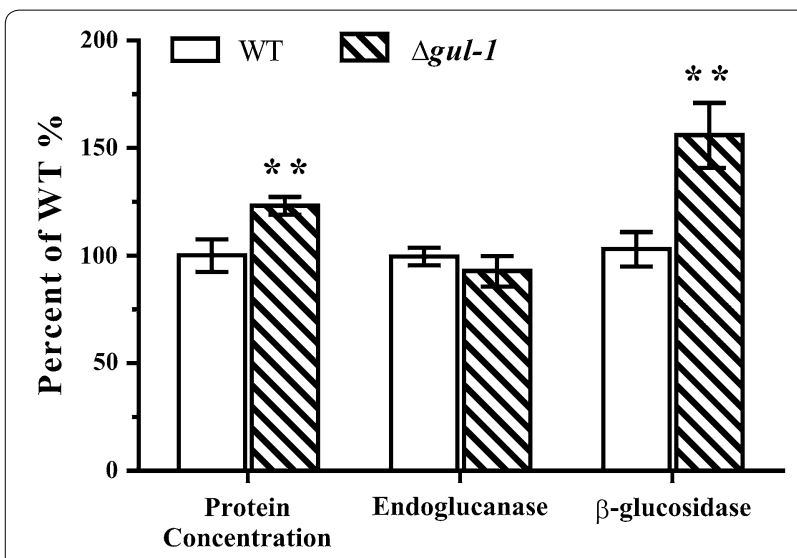

Fig. 6 Phenotype of WT and $\triangle g u l-1$ strains when grown on Avicel medium. Conidia from the wild type (WT) and the gul-1 knockout mutant ( $\Delta$ gul-1) were separately inoculated into Avicel medium and batch cultured. After 7 days, total extracellular protein concentration, endoglucanase activity and $\beta$-glucosidase activity were measured. Data were normalized to the WT control according to percentage. Values represent the means of at least three biological replicates, error bars show standard deviation. Statistical significance was performed using a two-tailed Student's $t$ test $\left({ }^{*} P<0.01\right)$

in expression level $>$ twofold. Among these genes, four GPI-anchored glycoside hydrolase genes (NCU09175, NCU01353, NCU05974 and NCU6781), which were probably involved in cell wall remodeling, were downregulated 2.1-, 7.1-, 3.4- and 6.7-fold in gul-1 mutant, respectively, suggesting a reorganized arrangement of the cell wall. Moreover, anchored cell wall genes $a c w-1$ (NCU08936), $a c w-3$ (NCU05667), acw-6 (NCU03530), and $a c w-9$ (NCU06185) were also significantly down-regulated in $\Delta g u l-1$. In S. cerevisiae, acw-1 ortholog (ecm33) played a critical role in cell wall organization. Deletion of ecm33 results in a weakened and disorganized cell wall [41]. On the contrary, non-anchored cell wall genes $n c w-3$ (NCU07817) and ncw-5 (NCU00716) were up-regulated 2.7- and 3.2-fold, respectively. Moreover, in S. cerevisiae, SUN4 is involved in cell wall remodeling, and regulated by the yeast GUL-1 homologue Ssd1 [21]. As expected, the cell wall synthesis gene (NCU02668), a homolog of $S$. cerevisiae sun4, was down-regulated 2.9-fold in $\Delta g u l$-1, suggesting a possible direct regulation of NCU02668 by GUL-1 in N. crassa. Furthermore, a previous study has demonstrated that hydrophobins play important roles in pellet formation. In Aspergillus nidulans, disruption of hydrophobin gene $\operatorname{rodA}$ led to a decrease in pellet biomass and size [42]. According to our results, the Class I hydrophobin gene eas (NCU08457) was down-regulated 15 -fold in the $\Delta g u l-1$ strain, whereas the Class II hydrophobin gene NCU08192 was up-regulated 6.2-fold, indicating that hyphal hydrophobicity might be changed in $\Delta$ gul-1. Taken together, the significant changes in expression of cell wall-related proteins suggested that the $\Delta g u l-1$ mutant has an abnormal cell wall structure, which might be the reason for pellet formation.

In addition, the expression levels of major cellulase genes were not affected by the gul-1 deletion, except that the extracellular $\beta$-glucosidase gene (NCU04952) had significantly higher expression level in $\Delta g u l-1$ (Fig. $7 \mathrm{~b}$ and c). These results are consistent with the enzyme activity assay shown in Fig. 6.

\section{Genetic engineering of $N$. crassa for hyper-cellulase production and lower viscosity}

Recent investigations have revealed that $N$. crassa is a good model system for unraveling the mechanisms of lignocellulose degradation [43, 44]. Meanwhile, several key genes involved in cellulase expression and secretion have been identified and characterized in N. crassa. NCU05137, which encodes a non-anchored cell wall protein $(\mathrm{NCW}-1)$, could be detected in the secreted proteome of cultures containing cellulose as sole carbon [45]. The disruption of $n c w-1$ resulted in significantly increased cellulase production and cellulolytic activity [12]. In addition, we previously reported that disrupting Ncap3m (NCU03998, which encodes the $\mu$ subunit of the adaptor protein 3 complex) also dramatically increases lignocellulase secretion [16]. Based on these findings, a hyper cellulase producing strain $\Delta n c w$ $1 \Delta N c a p 3 m$ was generated by sexual crosses. Compared to WT, the extracellular protein concentration of the $\Delta n c w-1 \Delta N c a p 3 m$ strain was improved by approximately $65 \%(\sim 0.8 \mathrm{~g} / \mathrm{L})$ and endoglucanase activity increased by about $73 \%$ (Fig. 8a). However, $\Delta n c w-1 \Delta N c a p 3 m$ exhibited poor rheological properties, and the viscosity of $\Delta n c w-1 \Delta N c a p 3 m$ was almost twofold higher than that of the WT. We therefore determined whether the rheological properties of the broth could be improved by deleting the gul-1 gene in $\Delta n c w-1 \Delta N c a p 3 m$. The triple deletion strain $(\Delta n c w-1 \Delta$ Ncap $3 m \Delta g u l-1)$ was obtained by crossing $\Delta g u l-1$ with $\Delta n c w-1 \Delta N c a p 3 m$, and the progeny were verified by PCR. Not surprisingly, the triple deletion strain grew as pellets (Fig. 8b), and the viscosity of $\Delta n c w$ $1 \Delta$ Ncap $3 m \Delta$ gul -1 was only $23 \%$ that of the double deletion strain $(\Delta n c w-1 \Delta N c a p 3 m)$, and $53 \%$ that of the WT strain (Fig. 8a). Production of extracellular protein by $\Delta n c w-1 \Delta$ Ncap $3 m \Delta$ gul-1 was significantly improved relative to $\Delta n c w-1 \Delta N c a p 3 m$. However, no significant differences in endoglucanase and $\beta$-glucosidase activities were apparent.

\section{Discussion}

In fungal fermentations, high apparent viscosity and nonNewtonian behavior of broths are critical problems in industrial application. Thus, controlling the morphology 

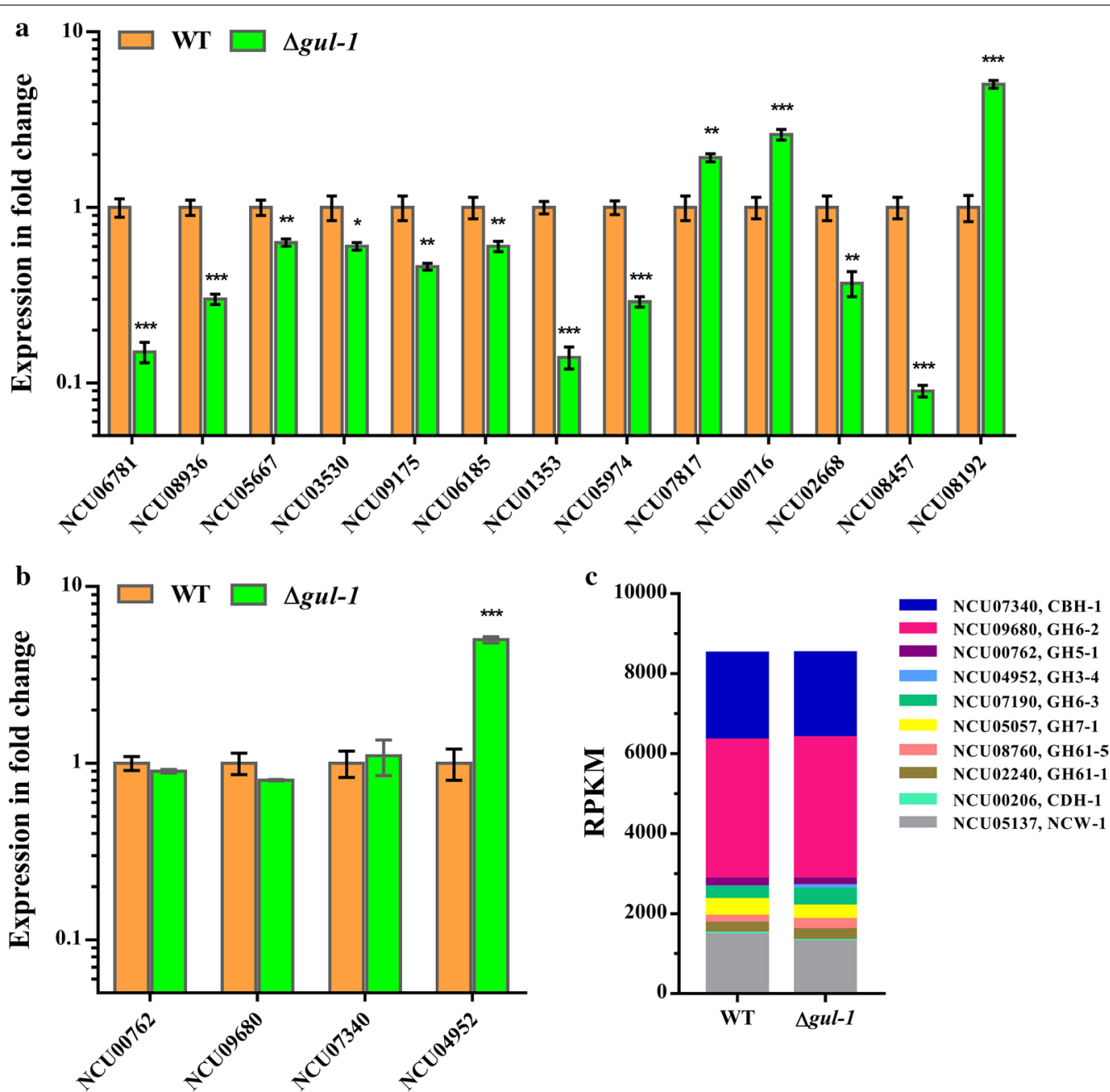

Fig. 7 Transcriptome analysis of the $\Delta$ gul-1 strain on Avicel medium. a Expression levels of genes encoding cell wall proteins in $\triangle$ gul-1 mutant relative to wild-type (WT) strain on Avicel. $\mathbf{b}$ Expression levels of major cellulase genes in $\triangle$ gul-1 mutant relative to the wild-type (WT) strain on Avicel. c Expression levels from RNA-seq data of genes encoding major secreted proteins from WT and $\triangle$ gul-1 when grown on Avicel medium. After $\triangle$ gul-1 and WT conidia were grown on Avicel for 3 days, the transcriptional abundance of major cellulase genes and cell wall protein genes was evaluated by RNA-seq and quantitative real-time PCR. Values represent the means of at least three biological replicates, error bars show standard deviation. Statistical significance was performed using a two-tailed Student's $t$ test $\left({ }^{*} P<0.05,{ }^{* *} P<0.01,{ }^{* * *} P<0.001\right)$

of filamentous fungus in submerged fermentations is a major challenge. Many strategies have been applied to solve these problems, principally by optimization of fermentation process parameters [5-8]. However, morphology control by altering chemical and physical factors is not sufficient. Moreover, these optimized parameters are not always suited for achieving maximum productivity. Recently, several attempts have been employed to control mycelial morphology by genetic modification. As previously reported, the motor proteins played critical roles in polarized growth in Aspergillus spp. Disruption of kinesin motor KipA in Aspergillus glaucus caused pellet growth in submerged cultivation and the aspergiolide A production was $82 \%$ higher than that of wild type strain [46]. Furthermore, disturbance of cell wall synthesis had significant influences on mycelial morphology [47]. In Aspergillus orzyae, disruption of chsB had no effect on enzyme production, but the viscosity was lower than that of parental strain [48]. In Penicillium chrysogenum, down-regulation of chitin synthase gene resulted in pellet growth in submerged culture, and also caused enhanced penicillin production [49]. Thus, rationally shaping mycelial morphology through genetic modification seems to be an attractive strategy. However, large-scale generation and screening of morphological mutants is difficult to achieve. Fortunately, N. crassa possesses a near full 
$\mathbf{a}$
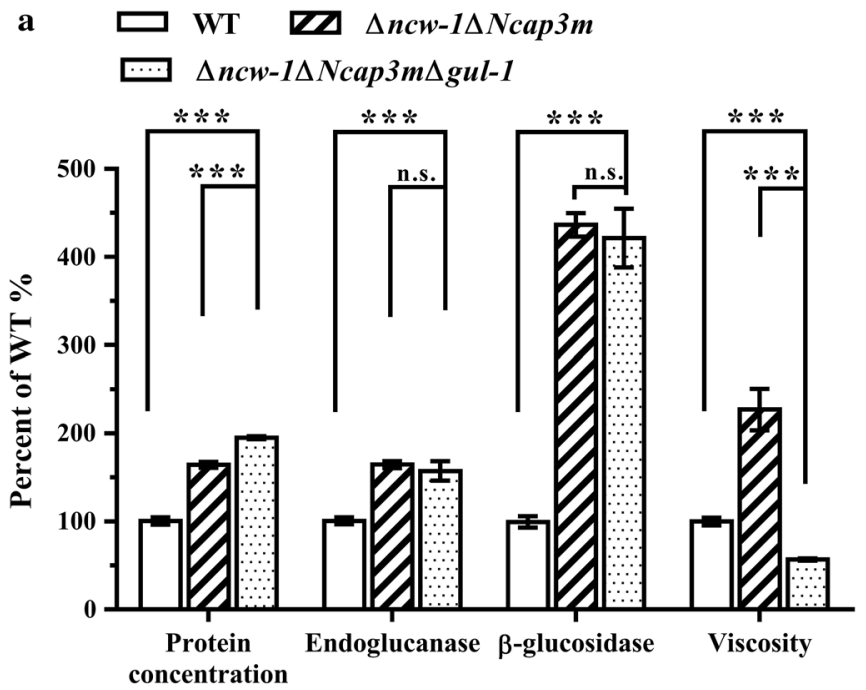

b

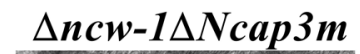

$\Delta$ ncw-1 1 Ncap3m $\Delta$ gul-1

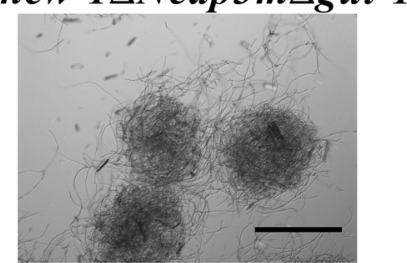

Fig. 8 Phenotype of $\triangle n c w-1 \Delta N c a p 3 m \Delta g u l-1$ triple mutant when grown on Avicel medium. Conidia of the wild type (WT), the double deletion strain $(\Delta n c w-1 \Delta N c a p 3 m)$ and the triple deletion strain ( $\triangle n c w-1 \Delta N c a p 3 m \Delta g u l-1)$ were separately inoculated into Avicel medium, and then cultured for 7 days. a Total extracellular protein concentration, endoglucanase activity, $\beta$-glucosidase activity and the viscosity of culture broth were measured and normalized to the WT according to percentage. Values represent the means of at least three biological replicates, error bars show standard deviation. Statistical significance was performed using a two-tailed Student's $t$ test $\left({ }^{* * *} P<0.001\right.$; n.s., not significant). b Mycelial morphologies of the triple deletion strain $(\Delta n c w-1 \Delta N c a p 3 m \Delta g u l-1)$ and its parental strain $(\Delta n c w-1 \Delta N c a p 3 m)$ after 7 days cultivation. The images were acquired by an Olympus SZX-7 stereomicroscopy with a digital camera attached. Scale bar is $300 \mu \mathrm{m}$

genome deletion strain collection [27]. In this work, we systematically screened the $90 \mathrm{~N}$. crassa morphological mutants to identify the critical genes that could influence mycelial morphology during submerged cultivation. The viscosity of fermentation broth was used to reflect mycelial morphology change. Fourteen mutants showed increased viscosity compared to the WT strain. Among these mutants, we found several genes involved in the proteasome pathway, e.g., NCU01368, NCU05295, NCU09366 and NCU06440. All these four genes encode different subunits of the proteasome, implying that interruption of the protein degradation pathway might influence mycelial morphology. Moreover, NCU00824 encodes a histone deacetylase which possibly contributes to chromatin structure modification. Previous work in the yeast $C$. albicans has demonstrated that histone deacetylase interacting with transcription factors plays a critical role in morphological transition [50]. The highviscosity phenotype induced by a defect in NCU00824 implies a close link between chromatin structure modification and morphology control in filamentous fungi.

Of most interest, we found that disruption of gul-1 (NCU01197) in N. crassa led to favorable morphological changes in submerged culture. The $\Delta g u l-1$ mutant grew as pellets and showed a low viscosity phenotype. Furthermore, scanning electron microscopy observations revealed that the cell wall structure was altered in the $\mathrm{gul}$ 1 mutant. Our results with Congo Red and Calcofluor
White also illustrated that gul-1 is required for cell wall integrity. Based on these results, we hypothesized that pellet formation is closely associated with changes in cell wall structure. In filamentous fungi, $\beta$-(1,3)-glucan and chitin are two major structural components of the fungal cell wall. However, according to our results, the transcript levels of genes encoding chitin and glucan synthases (chs1-7 and gls-1), which are involved in cell wall synthesis, were not changed by the gul-1 deletion (Additional file 6: Table S2). Moreover, the expression levels of chit-1 (NCU02184) and gh18-5 (NCU04554), which are involved in cell wall maintenance and remodeling [51], were also not altered in $\Delta g u l-1$ (Additional file 6: Table S2). It suggested that these genes are probably not involved in conferring the gul-1 phenotype. On the other hand, cell wall proteins are the important components of the fungal cell wall, and also play important roles in cell wall biosynthesis and interactions with external environment [40]. Intriguingly, the transcript abundance of several cell wall protein genes was found to be significantly altered in $\Delta g u l-1$. Among these genes, the GPI-anchored cell wall $\beta-1,3$-endoglucanase gene bgt-2 (NCU09175), which is seemingly involved in cell wall remodeling, was down-regulated 2.1-fold in $\Delta g u l-1$. A recent study also showed the cell wall architecture is altered in the $\Delta b g t$ 2 mutant [52]. Likewise, the transcript abundances of GPI-anchored glycoside hydrolases NCU05974 and NCU06781, the homologs of S. cerevisiae crh1 and 
Aspergillus fumigatus gel2, respectively, were also lower in $\Delta g u l-1$. It has been reported that both $S$. cerevisiae crh1 and A. fumigatus gel2 are required for normal cell wall structure. Loss of S. cerevisiae crh1 causes hypersensitivity to Congo Red and Calcofluor White, suggesting defects in cell wall structure [53]. In A. fumigatus, the gel2 disruption strain exhibits slower growth and an altered cell wall composition [54]. These implicated that down-regulation of both NCU05974 and NCU06781 may results in an abnormal cell wall structure, leading to influencing mycelial morphology during submerged cultivation. Besides that, other GPI-anchored cell wall proteins, which are of unknown function, are annotated as ACW (GPI-anchored cell wall protein) [40]. They may serve as important structural components of the wall, and play critical roles in maintaining cell wall stability and function [55]. For example, AfuEcm33, a homolog of the $N$. crassa GPI-anchored cell wall protein-1 (acw-1), has been shown to be involved in maintaining cell wall integrity and virulence in A. fumigatus [56]. It is worth noting that disruption of $A f u E c m 33$ results in increased cell-cell adhesion. The disruption strain forms large 'star-shaped' clusters of germinating conidia during submerged cultivation [56]. In Candida albicans, a similar aggregate phenotype has been also observed in the Caecm 33 deletion strain [57]. In this study, the GPI-anchored cell wall protein ACW-1 encoded by NCU08936 was found to be down-regulated in $\Delta g u l-1$, suggesting that $\mathrm{ACW}-1$ might, at least in part, contribute to pellet formation by increased cell-cell adhesion. Taken together, our results indicated that gul-1 affects mycelial morphology during submerged cultivation by influencing the expression of cell wall-related protein. However, a detailed mechanistic description of how the gul-1 influences these genes expression requires further investigation.

According to our results, the deletion of gul-1 led to a hypersecretion phenotype in $N$. crassa. When grown on $2 \%(\mathrm{w} / \mathrm{v})$ Avicel, the extracellular protein secreted by the $\Delta$ gul-1 mutant was about $25 \%$ higher than that in the WT, while only $\beta$-glucosidase activity was found to be improved. These results were also confirmed by our transcriptomic analysis (Fig. $7 \mathrm{~b}$ and c). However, the increase in activity was disproportionate to the increase in total protein, suggesting that the effect of $g u l-1$ on protein secretion is not due to increased transcription levels. Thus, we hypothesized that the defects in cell wall integrity benefit protein secretion. According to the 'bulk flow' hypothesis, growing hyphal tips are filled with vesicles that contain extracellular proteins, and these proteins get carried to the outer region of the wall for secretion [58]. However, some extracellular proteins might become trapped in the rigid cell wall. These 'trapped' enzymes could be released into an external medium through a weakening of cell wall integrity [59], which may explain the $\Delta g u l-1$ mutant having a higher protein secretion capacity. Similar results could be observed in the $N$. crassa slime mutant which has serious defects in cell wall synthesis [60].

Our previous study demonstrated that the disruption of $n c w-1$ led to enhanced cellulase production in N. crassa, but unfortunately the viscosity of $\Delta n c w-1$ was increased two fold [14]. A similar phenotype was also observed in the $\Delta n c w-1 \Delta N c a p 3 m$ strain. Having identified the impact of gul-1 disruption on mycelial morphology during submerged cultivation, we applied this approach to the hyper-cellulase producing strain $\Delta n c w-1 \Delta N c a p 3 m$. The triple deletion strain $(\Delta n c w-1 \Delta N c a p 3 m \Delta g u l-1)$ grew in pellet form and exhibited a low viscosity phenotype, indicating that gul-1 is a promising target gene for morphological improvement of hyper-cellulaseproducing strains. In addition, phylogenetic analyses demonstrated that GUL-1 is highly conserved in other industrial filamentous fungi, including Aspergillus niger (XP_001392470, identity 66\%), Myceliophthora thermophila (XP_003661716, 75\% identity) and Trichoderma reesei (XP_006964501, 78\% identity) (Additional file 8: Figure S5). Thus, manipulation of gul-1 homologs could be a highly useful strategy for morphology engineering of industrial filamentous fungi.

\section{Conclusions}

In this work, we systematically screened morphological mutants of $N$. crassa and identified several potential genes that affect mycelial morphology in submerged cultivation. Deletion of one of these genes, gul-1, resulted in the pellet form and enhanced protein secretion in $N$. crassa. Transcriptional profiling revealed that a deletion of gul-1 led to an alteration in transcription of genes encoding cell wall proteins, which may be the reason for changes in mycelial morphology during submerged cultivation. Furthermore, a significant reduction in viscosity of broth culture was obtained when $g u l-1$ was deleted from the hyper cellulolytic strain $\Delta n c w-1 \Delta N c a p 3 m$. These results indicated that gul-1 might be a potential target to control mycelial morphology in submerged cultivation. This work provides a novel strategy for morphological engineering of filamentous fungi through genetic modification, especially for industrially relevant species.

\section{Methods}

\section{Strains, growth conditions and microscopy}

Neurospora crassa strains were obtained from Fungal Genetics Stock Centre (FGSC), including wild type (WT, FGSC 2489, A), a his-3 mutant strain (FGSC 9716, his-3, a) and the morphological mutants. The his-3; $\Delta g u l-1$, a strain was obtained by crossing FGSC 9716 with FGSC 
11288 (NCU01197, A). Multiple deletion strains were made by performing sequential crosses. All of the constructed strains were verified by PCR.

To obtain conidia, $N$. crassa was grown on slant tubes containing Vogel's minimal media $(1 \times$ Vogel's salts, $2 \% \mathrm{w} / \mathrm{v}$ sucrose and $1.5 \% \mathrm{w} / \mathrm{v}$ agar) for 10 days at $28{ }^{\circ} \mathrm{C}$. For flask culture, 10-day-old conidia of $N$. crassa strains were suspended in sterile water and inoculated using a final concentration of $1 \times 10^{5}$ per $\mathrm{mL}$ into a $250-\mathrm{mL}$ Erlenmeyer flask containing $100 \mathrm{~mL}$ Avicel medium $(1 \times$ Vogel's salts, $2 \% \mathrm{w} / \mathrm{v}$ Avicel, $0.75 \% \mathrm{w} / \mathrm{v}$ yeast extract and $0.2 \% \mathrm{v} / \mathrm{v}$ Tween 80 ), then cultured for 7 days at $25^{\circ} \mathrm{C}$, with shaking at $200 \mathrm{rpm}$ under constant light. The observations were carried out on 7 consecutive days at $24 \mathrm{~h}$ intervals.

Microscopic observations were carried out using an OLYMPUS BX51 microscope equipped with a QImagingRetiga 2000R camera (QImaging, Surrey, Canada), and analyzed with the Image-Pro Express 6.3 software. The images were also acquired by an Olympus SZX-7 stereomicroscopy with a digital camera attached.

To compare the differences in cell surface structure between the WT and $\Delta g u l-1$, fungal conidia were incubated in Avicel medium at $25^{\circ} \mathrm{C}$ for 5 days. The harvested mycelia were fixed in $0.1 \mathrm{M}$ phosphate buffer $(\mathrm{pH} 7.2)$ containing a final concentration of $2.5 \%(\mathrm{w} / \mathrm{v})$ glutaraldehyde. The samples were rinsed in thrice-distilled PBS, and dehydrated with a series of ethanol solutions (30$100 \%, v / v)$. After which the samples were dried by critical point drying (Leica CPD300) and coated with platinum (Hitachi E-1045). Observations were conducted using a scanning electron microscope (Hitachi SU8010) operating at $1 \mathrm{kV}$.

\section{Plasmid construction and transformation}

Genomic DNA from the WT strain was extracted as described previously [61]. To complement $\Delta g u l-1$, the open reading frame (ORF) of gul-1 was cloned by PCR with primers ORF-F and ORF-R, and the fragment was inserted into the $\mathrm{XbaI}$ and PacI sites of pMF272 to form pMF272-Pc-gul-1-gfp. The promoter of gul-1 was amplified with primers $\mathrm{PF}$ and $\mathrm{PR}$, and then cloned into the NotI and XbaI sites of pMF272-Pc-gul-1-gfp to form pMF272-Pn-gul-1-gfp. The primers used in this study are listed in Additional file 9: Table S4. All PCR products in this study were cloned into the pGEM-T vector (Promega) and sequenced for confirmation.

Plasmid DNA $(10 \mu \mathrm{g})$ was transformed into a (his-3; $\Delta g u l-1$, a) strain as described previously [16]. The constructs were targeted to the his-3 locus by homologous recombination, and correct integration was confirmed by GFP fluorescence and PCR. To recover homokaryotic strains, $\mathrm{His}^{+} \mathrm{GFP}^{+}$transformants were crossed with
FGSC 11288 (NCU01197, A). Progeny were selected for histidine prototrophy and GFP fluorescence. The resulting complemented strains were termed Pc-gul-1 and Pn-gul-1.

\section{Enzyme activity assay}

For protein assays, $5 \mathrm{~mL}$ of culture supernatants were collected at each time point, centrifuged at $12,000 \mathrm{rpm}$ for $10 \mathrm{~min}$ to remove mycelia and stored at $4{ }^{\circ} \mathrm{C}$ for further analysis. Total extracellular proteins were quantified using a Bio-Rad Protein Assay kit based on absorbance at $595 \mathrm{~nm}$, with bovine serum albumin as the standard. The endoglucanase activity was determined using the azo-CMC assay kit according to manufacturer's instruction (Megazyme). We used $p$-nitrophenyl- $\beta$ $D$-glucopyranoside ( $p$ NPG) for the measurement of $\beta$-glucosidase activity as described previously [62]. Briefly, a $250 \mu \mathrm{L}$ culture supernatant that was diluted with $50 \mathrm{mM}$ sodium citrate ( $\mathrm{pH} 4.8$ ) was added to $250 \mu \mathrm{L}$ of $1 \mathrm{mg} / \mathrm{mL} p \mathrm{NPG}$, and then incubated immediately for $10 \mathrm{~min}$ at $50{ }^{\circ} \mathrm{C}$. The reaction mixture was terminated by adding $500 \mu \mathrm{L}$ of $1 \mathrm{M} \mathrm{Na}_{2} \mathrm{CO}_{3}$ and determined at an absorbance of $420 \mathrm{~nm}$. Inactive enzyme, which was boiled at $100{ }^{\circ} \mathrm{C}$ for $10 \mathrm{~min}$, was used as a control. $p \mathrm{NP}$ was used to generate a standard curve. One unit (U) of $\beta$-glucosidase activity was defined as the amount of $p$ NP released from the substrate per minute using $1 \mathrm{~mL}$ enzyme under the standard assay conditions.

\section{Fungal biomass assay and rheological measurement}

The dry weight of fungal biomass was indirectly measured as previously described [14]. Briefly, a 5-mL culture broth was centrifuged at $4000 \mathrm{rpm}$ for $10 \mathrm{~min}$, the supernatant was discarded, and the pellet was dried and weighed. The dried residue was resuspended in $3 \mathrm{~mL}$ of acetic nitric reagent $(80: 20, \mathrm{v} / \mathrm{v})$, and bathed with boiling water for $2 \mathrm{~h}$ to remove mycelia. The residual Avicel was washed thoroughly, then dried, and reweighed. Mycelial dry weight was defined as the dry weight of the original 5-mL culture minus that of residual Avicel.

Rheological properties of fermentation broth were measured with a Brookfield digital HBDV-III Ultra rheometer according to the manufacturer's instructions. Viscosity was measured as the torque exerted by the mycelial sample on the rheometer impeller at $50 \mathrm{rpm}$. Torque was recorded after the reading had stabilized (45-60 s).

\section{Oxidative stress, high osmotic stress and cell wall integrity test}

For plate assays, $5 \mu \mathrm{L}$ aliquots of conidial suspensions $\left(10^{7} \mathrm{~mL}^{-1}\right)$ were applied onto Vogel's solid medium (MM: $1 \times$ Vogel's salts, $2 \% \mathrm{w} / \mathrm{v}$ sucrose and $1.5 \% \mathrm{w} / \mathrm{v}$ agar) 
supplemented with $\mathrm{H}_{2} \mathrm{O}_{2}(10,20 \mathrm{mM})$, diamide $(6,9 \mu \mathrm{g} /$ $\mathrm{mL})$, methyl-viologen $(4.5,9 \mu \mathrm{g} / \mathrm{mL}), \mathrm{NaCl}(0.5,1.0 \mathrm{M})$, Congo Red $(1,2 \mathrm{mg} / \mathrm{mL})$ or Calcofluor White (200, $400 \mu \mathrm{g} / \mathrm{mL}$ ). Plates were incubated at $28{ }^{\circ} \mathrm{C}$ for $18 \mathrm{~h}$. All colonies were cross-measured to determine their growth indices under each stress.

\section{RNA extraction, sequencing and data analysis}

For gene expression analysis, conidia of $\Delta g u l-1$ and WT strains were separately inoculated into Avicel medium $(1 \times$ Vogel's salt, $2 \% \mathrm{w} / \mathrm{v}$ crystalline cellulose, $0.75 \% \mathrm{w} / \mathrm{v}$ yeast extract and $0.2 \% \mathrm{v} / \mathrm{v}$ Tween 80 ) and batch cultured for 3 days at $25{ }^{\circ} \mathrm{C}$ with constant light. Mycelia were harvested by vacuum filtration and frozen immediately in liquid nitrogen. Total RNA from frozen samples was isolated using Trizol reagent (Invitrogen) in accordance with the manufacturer's protocol, and further treated with DNase I (RNeasy Mini Kit, Qiagen). The RNA integrity was checked by agarose gel electrophoresis. RNA-seq was performed on the Illumina HiSeqTM 2000 platform of Beijing Genomics Institute (BGI, Shenzhen, China). Filtered clean reads were mapped against predicted transcripts from the $N$. crassa OR74R genome (version 12) [63] using TopHat (version 2.0.8b) [64]. The alignment results were stored in SAM format files for subsequent analysis. The counts of reads that uniquely mapped to only one gene were calculated for each gene by Htseq-count (http://www-huber.embl. de/users/anders/HTSeq) using SAM files and genome annotation as input. Abundance for each transcript was calculated using the reads per kilobase per million (RPKM) [65]. Genes with altered expression were performed by using R package NOISeq (version 2.6.0) [66] ( $Q$ value $\geq 0.95$ used as threshold, which approximately corresponds to a $\mid \log _{2}$ ratio $\mid \geq 1$ ). To discover significantly upregulated and downregulated genes between WT and $\Delta g u l-1$, only the genes with relative high transcriptional abundance (RPKM values above 20 in at least one strain) went into further analysis [67]. Expression differences detected by RNA-seq were also verified by RT-PCR. Profiling data are listed in Additional file 6: Table S2, and the sequence data produced in this study can be accessed (GEO: GSE113321).

\section{Quantitative real-time PCR}

Quantitative real-time PCR (qRT-PCR) was performed using a CFX96 real-time PCR detection system (BioRad) with reagents from TOYOBO (One-step qPCR Kit). All assays were performed in triplicate with actin (NCU04173) as the endogenous standard, according to the manufacturer's instruction. All primers used in this study were listed in Additional file 9: Table S4.

\section{Phylogenetic analysis}

Putative orthologs of gul-1 in selected fungal species were identified as best reciprocal BLAST hits from the National Center for Biotechnology Institute (NCBI) protein database. The phylogenetic analysis was carried out using the Neighbor-Joining in MEGA4 software. Bootstrap values were adjacent to each internal node, representing the percentage of 1000 bootstrap replicates.

\section{Statistical analyses}

Unless otherwise noted, all experiments were performed in triplicate and statistical tests for significance were determined by two-tailed Student's $t$ test.

\section{Additional files}

Additional file 1: Figure S1. Mycelial morphology of $\Delta g u l-1$ and wild type strains. Cultures were grown on Vogel's minimal medium for $18 \mathrm{~h}$ at $28^{\circ} \mathrm{C}$. Scale bar is $500 \mu \mathrm{m}$.

Additional file 2: Figure S2. Scanning electron micrographs of hyphal morphology of wild type and $\triangle$ gul-1 strains. Cultures were grown on Avicel medium for 5 days at $25^{\circ} \mathrm{C}$. Scale bar is $10 \mu \mathrm{m}$.

Additional file 3: Figure S3. Biomass accumulation of WT and $\triangle$ gul-1 mutant when grown on Avicel medium. Conidia from $\triangle$ gul-1 and wild type (WT) strains were separately inoculated into Avicel medium and batch cultured for 7 days. The biomass accumulation was measured. Values represent the means of at least three replicates, error bars show standard deviation.

Additional file 4: Figure S4. Phenotype of WT and $\Delta g u l-1$ strains when grown on different carbon sources. (A) Viscosity; (B) Fungal morphology: (C) Protein secretion. Conidia were inoculated into $100 \mathrm{~mL}$ liquid media $[1 \times$ Vogel's salts, $0.75 \% \mathrm{w} / \mathrm{v}$ yeast extract, $0.2 \% \mathrm{v} / \mathrm{v}$ Tween 80 and $2 \% \mathrm{w} / \mathrm{v}$ carbon source (sucrose, xylose or fructose)] at $10^{5}$ conidia/mL and grown at $25^{\circ} \mathrm{C}$ in constant light and shaking (200 rpm). Statistical significance was performed using a two-tailed Student's $t$-test $\left({ }^{*} P<0.05\right)$ Scale bar is $1500 \mu \mathrm{m}$.

Additional file 5: Table S1. Growth rates of wild type and gul-1 mutant. Aliquots of $5 \mu \mathrm{L} 1 \times 10^{7} \mathrm{~mL}^{-1}$ spore suspensions of WT, $\triangle$ gul-1, Pn-gul-1 and Pc-gul- 1 were incubated at $28^{\circ} \mathrm{C}$ for $18 \mathrm{~h}$ on MM plates.

Additional file 6: Table S2. Gene list of the 246 genes differentially expressed in $\triangle$ gul-1 as compared to WT on Avicel.

Additional file 7: Table S3. Comparative analysis of cell wall-related gene expression between $\triangle$ gul-1 and WT by RNA-seq.

Additional file 8: Figure S5. Phylogenetic analysis of GUL-1 and its homologs. MEGA 4 software was used to carry out the analysis. Bootstrap values are adjacent to each internal node, representing the percentage of 1,000 bootstrap replicates.

Additional file 9: Table S4. Primers used in this study.

\section{Authors' contributions}

$\mathrm{LL}$ and $\mathrm{CT}$ conceived and designed the project. LL, ZS, YC, QL and WS performed the experiments. $L L, J L$ and $C T$ analyzed the data. $L L$ and $C T$ wrote the manuscript. All authors read and approved the final manuscript. 


\section{Acknowledgements}

We thank Dr. Raymond J St. Leger from University of Maryland, College Park for revising the manuscript. We also thank Dr. Timothy C. Cairns for the critical discussions and Huanhuan Zhai for the technical assistance.

\section{Competing interests}

The authors declare that they have no competing interests.

\section{Availability of data and materials}

All data generated or analyzed during this study are included in this manuscript (and its Additional files).

\section{Consent for publication}

Not applicable.

\section{Ethics approval and consent to participate}

Not applicable.

\section{Funding}

This work was supported by the National Natural Science Foundation of China (31501007 and 31471186).

\section{Publisher's Note}

Springer Nature remains neutral with regard to jurisdictional claims in published maps and institutional affiliations.

Received: 6 March 2018 Accepted: 12 June 2018

Published online: 16 June 2018

\section{References}

1. Nevalainen KM, Te'o VS, Bergquist PL. Heterologous protein expression in filamentous fungi. Trends Biotechnol. 2005;23:468-74.

2. Meyer $V$. Genetic engineering of filamentous fungi-progress, obstacles and future trends. Biotechnol Adv. 2008:26:177-85.

3. Ward OP. Production of recombinant proteins by filamentous fungi. Biotechnol Adv. 2012;30:1119-39.

4. Li ZJ, Shukla V, Fordyce AP, Pedersen AG, Wenger KS, Marten MR. Fungal morphology and fragmentation behavior in a fed-batch Aspergillus oryzae fermentation at the production scale. Biotechnol Bioeng. 2000;70:300-12.

5. Amanullah A, Christensen LH, Hansen K, Nienow AW, Thomas CR. Dependence of morphology on agitation intensity in fed-batch cultures of Aspergillus oryzae and its implications for recombinant protein production. Biotechnol Bioeng. 2002;77:815-26.

6. Chao Y, Singh D, Yu L, Li Z, Chi Z, Chen S. Secretome characteristics of pelletized Trichoderma reesei and cellulase production. World J Microbiol Biotechnol. 2012;28:2635-41.

7. Nair RB, Lennartsson PR, Taherzadeh MJ. Mycelial pellet formation by edible ascomycete filamentous fungi, Neurospora intermedia. AMB Express. 2016:6:31

8. Abd-Aziz S, Fernandez CC, Salleh MM, Illias RM, Hassan MA. Effect of agitation and aeration rates on chitinase production using Trichoderma virens UKM1 in 2-I stirred tank reactor. Appl Biochem Biotechnol. 2008;150:193-204.

9. Bocking SP, Wiebe MG, Robson GD, Hansen K, Christiansen LH, Trinci AP. Effect of branch frequency in Aspergillus oryzae on protein secretion and culture viscosity. Biotechnol Bioeng. 1999;65:638-48.

10. Roche CM, Loros JJ, McCluskey K, Glass NL. Neurospora crassa: looking back and looking forward at a model microbe. Am J Bot. 2014;101:2022-35.

11. Dunlap JC, Borkovich KA, Henn MR, Turner GE, Sachs MS, Glass NL, McCluskey K, Plamann M, Galagan JE, Birren BW, et al. Enabling a community to dissect an organism: overview of the Neurospora functional genomics project. Adv Genet. 2007;57:49-96.

12. Tian C, Beeson WT, lavarone AT, Sun J, Marletta MA, Cate JH, Glass NL. Systems analysis of plant cell wall degradation by the model filamentous fungus Neurospora crassa. Proc Natl Acad Sci USA. 2009;106:22157-62.
13. Dogaris I, Mamma D, Kekos D. Biotechnological production of ethanol from renewable resources by Neurospora crassa: an alternative to conventional yeast fermentations? Appl Microbiol Biotechnol. 2013;97:1457-73.

14. Lin L, Chen Y, Li J, Wang S, Sun W, Tian C. Disruption of non-anchored cell wall protein NCW-1 promotes cellulase production by increasing cellobiose uptake in Neurospora crassa. Biotechnol Lett. 2016;39:545-51.

15. Fan F, Ma G, Li J, Liu Q, Benz JP, Tian C, Ma Y. Genome-wide analysis of the endoplasmic reticulum stress response during lignocellulase production in Neurospora crassa. Biotechnol Biofuels. 2015:8:66.

16. Pei X, Fan F, Lin L, Chen Y, Sun W, Zhang S, Tian C. Involvement of the adaptor protein 3 complex in lignocellulase secretion in Neurospora crassa revealed by comparative genomic screening. Biotechnol Biofuels. 2015;8:124.

17. Rajan JS, Virkar PD. Induced pelletized growth of Neurospora crassa for tyrosinase biosynthesis in airlift fermenters. Biotechnol Bioeng 1987:29:770-2

18. Wen SuW, Jun He B. Secreted enzyme production by fungal pellets in a perfusion bioreactor. J Biotechnol. 1997:54:43-52.

19. Kaeberlein M, Guarente L. Saccharomyces cerevisiae MPT5 and SSD1 function in parallel pathways to promote cell wall integrity. Genetics. 2002;160:83-95.

20. Hogan DJ, Riordan DP, Gerber AP, Herschlag D, Brown PO. Diverse RNAbinding proteins interact with functionally related sets of RNAs, suggesting an extensive regulatory system. PLoS Biol. 2008;6:e255.

21. Jansen JM, Wanless AG, Seidel CW, Weiss EL. Cbk1 regulation of the RNAbinding protein Ssd1 integrates cell fate with translational control. Curr Biol. 2009:19:2114-20.

22. Wheeler RT, Kupiec M, Magnelli P, Abeijon C, Fink GR. A Saccharomyces cerevisiae mutant with increased virulence. Proc Natl Acad Sci USA. 2003;100:2766-70.

23. Seiler S, Vogt N, Ziv C, Gorovits R, Yarden O. The STE20/germinal center kinase POD6 interacts with the NDR kinase COT1 and is involved in polar tip extension in Neurospora crassa. Mol Biol Cell. 2006;17:4080-92.

24. Herold I, Yarden O. Regulation of Neurospora crassa cell wall remodeling via the cot-1 pathway is mediated by gul-1. Curr Genet. 2017:63:145-59.

25. Yarden O, Plamann M, Ebbole DJ, Yanofsky C. cot-1, a gene required for hyphal elongation in Neurospora crassa, encodes a protein kinase. EMBO J. 1992:11:2159-66.

26. Terenzi HF, Reissig JL. Modifiers of the cot gene in Neurospora: the gulliver mutants. Genetics. 1967;56:321-9.

27. Colot HV, Park G, Turner GE, Ringelberg C, Crew CM, Litvinkova L, Weiss RL, Borkovich KA, Dunlap JC. A high-throughput gene knockout procedure for Neurospora reveals functions for multiple transcription factors. Proc Natl Acad Sci USA. 2006;103:10352-7.

28. Watters MK, Boersma M, Johnson $M$, Reyes $C$, Westrick E, Lindamood E. A screen for Neurospora knockout mutants displaying growth rate dependent branch density. Fungal Biol. 2011;115:296-301.

29. Papagianni M. Fungal morphology and metabolite production in submerged mycelial processes. Biotechnol Adv. 2004:22:189-259.

30. Tanaka S, Yamada K, Yabumoto K, Fujii S, Huser A, Tsuji G, Koga H, Dohi K, Mori M, Shiraishi T, et al. Saccharomyces cerevisiae SSD1 orthologues are essential for host infection by the ascomycete plant pathogens Colletotrichum lagenarium and Magnaporthe grisea. Mol Microbiol. 2007;64:1332-49.

31. Kurischko C, Kuravi VK, Herbert CJ, Luca FC. Nucleocytoplasmic shuttling of Ssd 1 defines the destiny of its bound mRNAs. Mol Microbiol. 2011:81:831-49.

32. Ba ANN, Pogoutse A, Provart N, Moses AM. NLStradamus: a simple Hidden Markov Model for nuclear localization signal prediction. BMC Bioinform. 2009:10:202.

33. Kopecka M, Gabriel M. The influence of congo red on the cell wall and $(1 \rightarrow 3)$-beta-D-glucan microfibril biogenesis in Saccharomyces cerevisiae. Arch Microbiol. 1992;158:115-26.

34. Ram AF, Klis FM. Identification of fungal cell wall mutants using susceptibility assays based on Calcofluor white and Congo red. Nat Protoc 2006;1:2253-6.

35. Collinson LP, Dawes IW. Inducibility of the response of yeast cells to peroxide stress. J Gen Microbiol. 1992;138:329-35.

36. Wemmie JA, Steggerda SM, Moye-Rowley WS. The Saccharomyces cerevisiae AP-1 protein discriminates between oxidative stress elicited by the oxidants H2O2 and diamide. J Biol Chem. 1997:272·7908-14. 
37. Srijaruskul K, Charoenlap N, Namchaiw P, Chattrakarn S, Giengkam S, Mongkolsuk S, Vattanaviboon P. Regulation by SoxR of mfsA, which encodes a major facilitator protein involved in paraquat resistance in Stenotrophomonas maltophilia. PLoS ONE. 2015;10:e0123699.

38. Allgaier S, Taylor RD, Brudnaya Y, Jacobson DJ, Cambareri E, Stuart WD. Vaccine production in Neurospora crassa. Biologicals. 2009;37:128-32.

39. Zhang J, Zhang J. The filamentous fungal pellet and forces driving its formation. Crit Rev Biotechnol. 2016;36:1066-77.

40. Maddi A, Bowman SM, Free SJ. Trifluoromethanesulfonic acid-based proteomic analysis of cell wall and secreted proteins of the ascomycetous fungi Neurospora crassa and Candida albicans. Fungal Genet Biol. 2009:46:768-81.

41. Pardo M, Monteoliva L, Vazquez P, Martinez R, Molero G, Nombela C, Gil C. PST1 and ECM33 encode two yeast cell surface GPI proteins important for cell wall integrity. Microbiology. 2004;150:4157-70.

42. Dynesen J, Nielsen J. Surface hydrophobicity of Aspergillus nidulans conidiospores and its role in pellet formation. Biotechnol Prog. 2003:19:1049-52.

43. Znameroski EA, Glass NL. Using a model filamentous fungus to unravel mechanisms of lignocellulose deconstruction. Biotechnol Biofuels. 2013;6:6.

44. Coradetti ST, Craig JP, Xiong Y, Shock T, Tian C, Glass NL. Conserved and essential transcription factors for cellulase gene expression in ascomycete fungi. Proc Natl Acad Sci USA. 2012;109:7397-402.

45. Phillips CM, lavarone AT, Marletta MA. Quantitative proteomic approach for cellulose degradation by Neurospora crassa. J Proteome Res. 2011;10:4177-85

46. Cai M, Zhang Y, Hu W, Shen W, Yu Z, Zhou W, Jiang T, Zhou X, Zhang Y. Genetically shaping morphology of the filamentous fungus Aspergillus glaucus for production of antitumor polyketide aspergiolide A. Microb Cell Fact. 2014:13:73.

47. Bowman SM, Free SJ. The structure and synthesis of the fungal cell wall. BioEssays. 2006;28:799-808.

48. Muller C, Hansen K, Szabo P, Nielsen J. Effect of deletion of chitin synthase genes on mycelial morphology and culture viscosity in Aspergillus oryzae. Biotechnol Bioeng. 2003;81:525-34

49. Liu H, Zheng Z, Wang P, Gong G, Wang L, Zhao G. Morphological changes induced by class III chitin synthase gene silencing could enhance penicillin production of Penicillium chrysogenum. Appl Microbiol Biotechnol. 2013;97:3363-72

50. Kim J, Lee JE, Lee JS. Histone deacetylase-mediated morphological transition in Candida albicans. J Microbiol. 2015:53:805-11.

51. Kovacs Z, Szarka M, Kovacs S, Boczonadi I, Emri T, Abe K, Pocsi I, Pusztahelyi T. Effect of cell wall integrity stress and RImA transcription factor on asexual development and autolysis in Aspergillus nidulans. Fungal Genet Biol. 2013;54:1-14

52. Martinez-Nunez L, Riquelme M. Role of BGT-1 and BGT-2, two predicted GPI-anchored glycoside hydrolases/glycosyltransferases, in cell wall remodeling in Neurospora crassa. Fungal Genet Biol. 2015;85:58-70.
53. Cabib E, Blanco N, Grau C, Rodriguez-Pena JM, Arroyo J. Crh1 p and Crh2p are required for the cross-linking of chitin to beta(1-6)glucan in the Saccharomyces cerevisiae cell wall. Mol Microbiol. 2007;63:921-35.

54. Mouyna I, Morelle W, Vai M, Monod M, Lechenne B, Fontaine T, Beauvais A, Sarfati J, Prevost MC, Henry C, Latge JP. Deletion of GEL2 encoding for a beta(1-3)glucanosyltransferase affects morphogenesis and virulence in Aspergillus fumigatus. Mol Microbiol. 2005;56:1675-88.

55. Bowman SM, Piwowar A, Al Dabbous M, Vierula J, Free SJ. Mutational analysis of the glycosylphosphatidylinositol (GPI) anchor pathway demonstrates that GPI-anchored proteins are required for cell wall biogenesis and normal hyphal growth in Neurospora crassa. Eukaryot Cell. 2006:5:587-600.

56. Romano J, Nimrod G, Ben-Tal N, Shadkchan Y, Baruch K, Sharon H, Osherov N. Disruption of the Aspergillus fumigatus ECM33 homologue results in rapid conidial germination, antifungal resistance and hypervirulence. Microbiology. 2006;152:1919-28.

57. Martinez-Lopez R, Monteoliva L, Diez-Orejas R, Nombela C, Gil C. The GPI-anchored protein CaEcm33p is required for cell wall integrity, morphogenesis and virulence in Candida albicans. Microbiology. 2004:150:3341-54.

58. Wessels JGH. Tansley Review No. 45 Wall growth, protein excretion and morphogenesis in fungi. New Phytol. 1993;123:397-413.

59. Peberdy JF. Protein secretion in filamentous fungi-trying to understand a highly productive black box. Trends Biotechnol. 1994;12:50-7.

60. Bigger $\mathrm{CH}$, White MR, Braymer $\mathrm{H}$. Ultrastructure and invertase secretion of the slime mutant of Neurospora crassa. J Gen Microbiol. 1972;71:159-66.

61. Lin L, Fang W, Liao X, Wang F, Wei D, St Leger RJ. The MrCYP52 cytochrome $\mathrm{P} 450$ monoxygenase gene of Metarhizium robertsii is important for utilizing insect epicuticular hydrocarbons. PLOS ONE. 2011;6:e28984

62. Wang B, Cai P, Sun W, Li J, Tian C, Ma Y. A transcriptomic analysis of Neurospora crassa using five major crop residues and the novel role of the sporulation regulator $r c a-1$ in lignocellulase production. Biotechnol Biofuels. 2015;8:21

63. Galagan JE, Calvo SE, Borkovich KA, Selker EU, Read ND, Jaffe D, FitzHugh W, Ma LJ, Smirnov S, Purcell S, et al. The genome sequence of the filamentous fungus Neurospora crassa. Nature. 2003;422:859-68.

64. Kim D, Pertea G, Trapnell C, Pimentel H, Kelley R, Salzberg SL. TopHat2: accurate alignment of transcriptomes in the presence of insertions, deletions and gene fusions. Genome Biol. 2013;14:R36.

65. Mortazavi A, Williams BA, McCue K, Schaeffer L, Wold B. Mapping and quantifying mammalian transcriptomes by RNA-Seq. Nat Methods. 2008;5:621-8.

66. Tarazona S, Garcia-Alcalde F, Dopazo J, Ferrer A, Conesa A. Differential expression in RNA-seq: a matter of depth. Genome Res. 2011;21:2213-23.

67. McIntyre LM, Lopiano KK, Morse AM, Amin V, Oberg AL, Young LJ, Nuzhdin SV. RNA-seq: technical variability and sampling. BMC Genomics. 2011;12:293.

\footnotetext{
Ready to submit your research? Choose BMC and benefit from:

- fast, convenient online submission

- thorough peer review by experienced researchers in your field

- rapid publication on acceptance

- support for research data, including large and complex data types

- gold Open Access which fosters wider collaboration and increased citations

- maximum visibility for your research: over 100M website views per year
}

At BMC, research is always in progress.

Learn more biomedcentral.com/submissions 